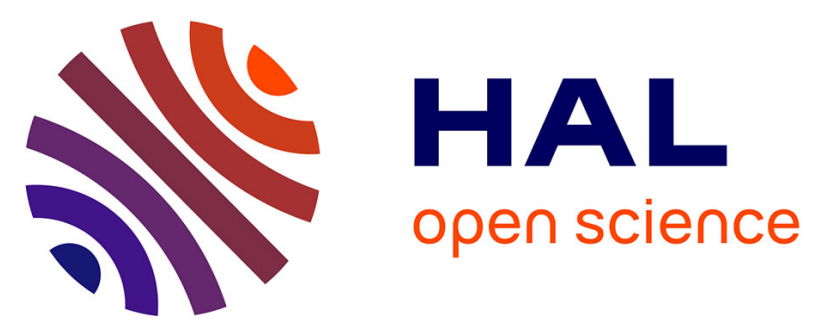

\title{
Association of TP53 mutations with response and longer survival under immune checkpoint inhibitors in advanced non-small-cell lung cancer
}

Sandra Assoun, Nathalie Theou-Anton, Marina Nguenang, Aurélie Cazes, Claire Danel, Baptiste Abbar, Johan Pluvy, Valérie Gounant, Antoine Khalil, Céline Namour, et al.

\section{To cite this version:}

Sandra Assoun, Nathalie Theou-Anton, Marina Nguenang, Aurélie Cazes, Claire Danel, et al.. Association of TP53 mutations with response and longer survival under immune checkpoint inhibitors in advanced non-small-cell lung cancer. Lung Cancer, 2019, 132, pp.65 - 71. 10.1016/j.lungcan.2019.04.005 . hal-03477631

\section{HAL Id: hal-03477631 \\ https://hal.science/hal-03477631}

Submitted on 20 Dec 2021

HAL is a multi-disciplinary open access archive for the deposit and dissemination of scientific research documents, whether they are published or not. The documents may come from teaching and research institutions in France or abroad, or from public or private research centers.
L'archive ouverte pluridisciplinaire HAL, est destinée au dépôt et à la diffusion de documents scientifiques de niveau recherche, publiés ou non, émanant des établissements d'enseignement et de recherche français ou étrangers, des laboratoires publics ou privés.

\section{(ㄷ)(1) $\$$}

Distributed under a Creative Commons Attribution - NonCommerciall 4.0 International 


\section{Association of TP53 Mutations with Response and Longer Survival under Immune Checkpoint Inhibitors in Advanced Non-Small-Cell \\ Lung Cancer}

Sandra Assoun ${ }^{\mathrm{a}, \mathrm{b}}$, Nathalie Theou-Anton ${ }^{\mathrm{c}}$, Marina Nguenang ${ }^{\mathrm{a}}$, Aurélie Cazes ${ }^{\mathrm{d}}$, Claire Danel ${ }^{\mathrm{d}}$,Baptiste Abbar ${ }^{\mathrm{a}}$, Johan Pluvy ${ }^{\mathrm{a}}$, Valérie Gounant ${ }^{\mathrm{a}}$, Antoine Khalile, Céline Namour a, Solenn Brosseau a,b,f , Gérard Zalcman ${ }^{a, b, f,{ }^{*}}$

aThoracic Oncology Department, University Hospital Bichat-Claude Bernard, Assistance Publique-Hôpitaux de Paris (AP-HP), 46 rue Henri Huchard, 75018 Paris, France

bU830 INSERM "Genetics and biology of cancers", Research Centre, Institut Curie, 26 rue d'Ulm, 75005 Paris, France

'Genetics Department, University Hospital Bichat-Claude Bernard, Assistance Publique-Hôpitaux de Paris (AP-HP), 46 rue Henri Huchard, 75018 Paris, France

dPathology Department, University Hospital Bichat-Claude Bernard, Assistance Publique-Hôpitaux de Paris (AP-HP), 46 rue Henri Huchard, 75018 Paris, France

eRadiology Department, University Hospital Bichat-Claude Bernard, Assistance Publique-Hôpitaux de Paris (AP-HP), 46 rue Henri Huchard, 75018 Paris, France

${ }^{f}$ Medicine Faculty, University Paris-Diderot, 46 rue Henri Huchard, 75018 Paris, France

${ }^{*}$ Corresponding author. 


\section{Disclosures:}

G. Zalcman declare grants and personal fees for its Institution from Pfizer, Roche, BMS, MSD, Astra-Zeneca, Boerhinger but not in relation to this submission.

V. Gounant declare personal fees from Roche, Astra-Zeneca, Lilly, BMS but not in relation to this submission

A. Cazes declare personal fees from BMS, Roche and MSD but not in relation to this submission

\section{Address for correspondence:}

Gérard Zalcman, MD, Service d'oncologie thoracique,

Hôpital Bichat-Claude Bernard, 46 rue Henri Huchard, 75877 Paris Cedex 18,

France. E-mail: gerard.zalcman@aphp.fr 


\section{ABSTRACT}

Introduction: Tumor mutational burden (TMB) correlates with response to immune checkpoint inhibitors (ICl) in advanced non-small-cell lung cancer (aNSCLC). We hypothesized that TP53 mutations could reflect TMB and be associated with ICI benefit.

Methods:TP53 mutations were assessed by next-generation sequencing in aNSCLC patients treated with programmed death-1 (PD-1) blockers. Clinical data, tumor programmed death ligand-1 (PD-L1) expression, and KRAS mutational status were collected. The primary endpoint was overall survival (OS).

Results: In total, 72 patients (median [interquartile range] age: 61 [33-83] years) were included; 52 (72\%) were male; 39 (54\%) had performance status $0-1 ; 53$ (74\%) had adenocarcinoma; 20 (28\%) received first-line ICI, 52 (72\%) second line or more. In 65 patients with available data, 36 (55\%) expressed PD-L1 in $\geq 50 \%$ of tumor cells, $20(31 \%)$ in $1-49 \%$ of cells, and nine (14\%) were PD-L1-negative. Non-synonymous TP53 mutations were observed in 41 (57\%) and 25 (35\%) harbored KRAS-mutated tumors. After a median follow-up of 15.2 months (95\% confidence interval [CI] 10.3$17.4 \mathrm{~m}$ ), the median OS in the TP53-mutated group was 18.1 months (95\% Cl 6.6-not reached), vs. 8.1 months $(95 \% \mathrm{Cl} 2.2-14.5$, hazard ratio $[\mathrm{HR}]=0.48 ; 95 \% \mathrm{Cl} 0.25-$ 0.95, $\mathrm{p}=0.04$ ) in the TP53-wild-type group. Median progression-free survival was significantly longer in TP53-mutated patients (4.5 months, 95\% Cl 2.8-18.1 versus $1.4,95 \% \mathrm{Cl} 1.1-3.5 ; \mathrm{p}=0.03)$, although TP53 mutation status failed to significantly influence PFS in the multivariate analysis $(p=0.32)$. Objective response rate $(O R R)$ was higher in patients with TP53 mutation (51.2\% vs. $20.7 \% ; \mathrm{p}=0.01)$. In multivariate analysis, TP53 mutations independently associated with longer OS (HR=0.35, 95\% Cl 0.16-0.77, $\mathrm{p}=0.009$ ). 
Conclusions: TP53-mutated status correlated with immunotherapy OS benefit in aNSCLC.

Keywords: Non-small-cell lung cancer; TP53 mutations; Tumor mutational burden; Immune checkpoint inhibitors

\section{Highlights}

- $\quad$ Frequent smoking-induced TP53 mutations in NSCLC lead to genetic instability

- Genetic instability could drive sensitivity to immunotherapy via neo-antigens

- TP53 mutations were found to actually drive longer OS upon immunotherapy. 


\section{Introduction}

The emergence of immune checkpoint inhibitors (ICI) has significantly influenced clinical therapeutic strategies for most cancer subtypes, notably in advanced nonsmall-cell lung cancer (aNSCLC). Programmed cell death-1 (PD-1) inhibitors, such as nivolumab or pembrolizumab, and programmed cell death ligand-1 (PD-L1) inhibitors (e.g. atezolizumab) have significantly improved progression-free survival (PFS) and overall survival (OS) of patients with aNSCLC, achieving outstanding duration of disease control compared to standard platinum-based frontline chemotherapy or second-line docetaxel chemotherapy [1-3]. However, only 20 to $25 \%$ of patients treated with immunotherapy derive bona fide benefit from this therapy, and determinants of response remain desperately elusive. To date, the only approved predictive biomarkers of $\mathrm{ICl}$ efficacy are microsatellite instability status $[4,5]$ and strong PD-L1 expression, assessed by immunohistochemical analysis for pembrolizumab in aNSCLC in first line [3]. Nonetheless, although PD-L1 tumor cell expression appears positively correlated to $\mathrm{ICl}$ efficacy [6], a significant proportion of selected patients with positive PD-L1 expression do not respond to ICI, or even show disease hyper-progression under treatment [7]. Conversely, patients with PD-L1negative tumors can surprisingly also manifest significant response to $\mathrm{ICl}$. Thus, identifying more robust predictive tools of response to ICI in NSCLC patients is an urgent need that still has yet to be met.

Recently, several studies provided compelling evidence that tumor mutational burden (TMB) could predict the potential activity of immunotherapy in numerous tumor types, including NSCLC $[8,9]$. By generating impaired cellular proteins recognized as neoantigens by immune cells, the resulting genetic instability can enhance tumor 
immunogenicity, thereby optimizing the antitumor cytotoxicity of $\mathrm{T}$ lymphocytes, reinstated by $\mathrm{ICl}$ therapy. As such, it has been suggested that mutations in oncogenes such as K-RAS are associated with favorable outcomes under $\mathrm{ICI}$ therapy in NSCLC patients $[10,11]$, though this effect is thought to be merely mediated through high TMB [12], while, conversely, EGFR mutations were associated with low mutational burden and lower rates of response to ICI [9]. Hailed as a historic "guardian of genome integrity", the TP53 gene may also constitute a relevant tool to indirectly quantify TMB [13]. Moreover, several studies demonstrated that PD-L1 expression was boosted in TP53-mutated tumors, whether TP53 status was assessed indirectly by immunohistochemistry analysis [14] or directly using whole-exome sequencing (WES) [11]. Thus, in a recent study, Dong et al. retrospectively showed in 30 aNSCLC patients treated with pembrolizumab that median PFS was significantly longer in the TP53-mutated group than in the TP53wild-type group (14.5 versus 3.5 months, $p=0.042$ ) [11]. However, these interesting results were not adjusted for the clinical and pathological features likely to influence response to ICI. Finally, using WES, the influence of individual genes within the TMB variable was analyzed to identify whether a limited number of mutational events could drive the predictive effect of TMB on PFS in patients treated with combined PD-1 and cytotoxic T-lymphocyte-associated protein 4 (CTLA-4) blockade [15]. TP53 mutations were identified as key events driving this predictive effect, while STK11 and PTEN mutations were associated with worse response to this combined $\mathrm{ICI}$ treatment, suggesting that a mutational signature incorporating these alterations with positive and negative values should be assessed, since it is easier by far to obtain tumor specimens from patients, to perform targeted NGS assessing such genes, than generate the expansive and complicated TMB in routine practice. 
We hypothesized that TP53 mutational status determined by routine targeted nextgeneration sequencing (NGS) diagnosis may correlate with response to $\mathrm{ICl}$ (either as monotherapy or double PD-1 and CTLA-4 blockade). We focused on aNSCLC patients treated in a University center, either in registered indications or in clinical trials. We also hypothesized that TP53 mutational status could be used as a prognostic biomarker in NSCLC patients treated with ICI in routine clinical practice.

\section{Materials and Methods}

\subsection{Patients and Methods}

We conducted a single-center retrospective study on consecutive aNSCLC patients treated with $\mathrm{ICI}$ in our university thoracic oncology department from September 2015 to November 2017. All patients were selected using our drug prescription software and treated with nivolumab, with or without CTLA-4 blocker ipilimumab, or pembrolizumab. Out of the 122 initially-identified consecutive patients, we only included those with NGS diagnosis available, performed on tumor tissue sampled before initiating $\mathrm{ICI}$. Patients were included whether they received $\mathrm{ICI}$ therapy as a standard of care for registered drugs, as participants in a clinical trial for other drugs or combinations or as a nominative temporary authorization for use (ATU) for drugs awaiting French registration after obtaining European Medicines Agency (EMA) registration, due to positive Phase 3 clinical trials, or as compassionate use after validation by our multidisciplinary tumor board (MTB), based on the lack of any other recognized therapeutic option. Clinical, biological, pathological, and molecular data were retrospectively collected from digital patient files. Responses were systematically evaluated by an MTB comprising an expert thoracic radiologist (AK), 
according to Response Evaluation Criteria In Solid Tumors (RECIST) rules. Immune RECIST criteria were not used in this study.

All patients were informed that their tumor samples were routinely analyzed at a molecular level for diagnosis purposes, and that they had the possibility to express their opposition to such routine analyses, according French law. This study was registered at the National Commission for Computing Liberties (CNIL registration number \# 2161770) and received approval from the Institutional Review Board of the French-learned Society for Respiratory medicine-Société de Pneumologie de Langue Française (CEPRO number \#2018-008), according to French regulatory rules for purely observational retrospective studies.

Tumor genomic profiling was performed as a routine reimbursed diagnostic procedure using targeted somatic NGS at the Bichat University Hospital genetics department, for advanced NSCLC. The process involved extraction of DNA, performed using Maxwell automaton (Promega, Madison, Wisconsin, USA) with the FFPE Plus LEV DNA kit, then search for hotspots and targeted regions 25 known genes using NGS (S5XL - Life Technologies, USA), data analysis was carried out on Torrent Suite and Ion reporter (Life Technologies). The genes amplified using the NGS panel CEIVD targeted kit, Oncomine tumor solid DNA (OST) and complementary panel OST+ (Life Technologies) are described in Table 1. The sequenced TP53 gene regions are depicted in Figure 1S. The structural and functional consequences of each TP53 mutation were verified on the International Agency for Research on Cancer (IARC) database [16,17]. Patients harboring synonymous TP53 mutations or TP53 mutations considered neutral according to the IARC database (especially c.217G>C p.V73L in exon 4) were included in the TP53 non mutated group. Data for PD-L1 expression was analyzed on tumor cells using 
immunohistochemistry with E1L3N antibody (Cell Signaling Technology, Danvers, MA, USA), as previously described, with a published laboratory-developed test (LDT) on a Leica Bond III platform [18,19]. We applied a cut-off for PD-L1 expression positivity of at least $1 \%$ of tumor cells, in samples containing at least 200 tumor cells, evaluated by two expert thoracic pathologists from the multicentric French panel for PD-L1 IHC testing (AC \& CD).

\subsection{Outcomes}

The primary endpoint was OS, defined as time from $\mathrm{ICl}$ initiation to death due to any cause. Patients who did not die were censored at the date of last follow-up. Secondary endpoints included PFS, defined by the time from ICI initiation to disease progression (as assessed by MTB) or death due to any cause, objective response rate (ORR), and disease control rate (DCR). Response was evaluated according to RECIST Version 1.1 criteria by an MTB including a thoracic radiologist expert (AK) at 8 weeks and then every 3 months until progression. Patients who exhibited no progression were censored at the date of last follow-up.

\subsection{Statistical Analysis}

Mean and median values of continuous variables were calculated for the population description, while categorical variables were described with frequencies and percentages. For baseline categorical variables, the two groups of NSCLC patients based on TP53 mutation status were compared using a Chi2 test or a Fisher's exact test for smaller sample sizes $(\leq 5)$. Univariate analysis by logistic regression was used to determine the variables associated with ORR. Unadjusted Odds Ratio (OR) with $95 \%$ Confidence Interval $(\mathrm{Cl})$ were reported. Multivariate analysis was 
performed using logistic regression. The variables associated with ORR ( $p$ value $\leq$ 0.20) in the univariate analysis were included in multivariate model. Kaplan-Meier analysis and log-rank test were respectively used to estimate the median survival times and their $95 \% \mathrm{Cl}$, and statistical significance for the two subgroups: TP53mutated and TP53-wild-type. Hazard Ratios (HR) and their 95\% Cl were calculated from univariate analyses with Cox proportional hazards models. Multivariate Cox analyses were performed using stepwise regression after checking the proportional hazard hypothesis graphically for all variables, and the absence of multicolinearity between variables by calculating inflation variance factors. Variables with more than $5 \%$ missing data were not introduced in the multivariate analysis. The variables tested in the univariate analyses of OS and PFS were gender, age, smoking status, performance status (PS), histological subtype, number of lines or treatment, PD-L1 expression level, KRAS and TP53 mutational status. Only variables that showed association with survival ( $p$-value set at $<0.20$ ) were introduced in the multivariate models of OS and PFS, with three additional clinical variables (gender, age and smoking status) forced in the OS multivariate model because of their clinical interest. Findings were considered statistically significant if two-sided $p$ values were $<0.05$. All statistical analyses were performed using SAS ${ }^{T M}$ version 9.4 software, University Edition for Windows ${ }^{\mathrm{TM}}$. Median follow-up was evaluated by the reverse Kaplan-Meier method. We censored follow-up on February 26th, 2018.

\section{Results}

Out of 122 patients with aNSCLC treated with ICI from September 2015 to November 2017, 72 (59.0\%) had targeted NGS with TP53 gene status available for analysis. Of all the patients with no NGS available ( $n=50), 32(64.0 \%)$ presented with squamous 
NSCLC (understandably so given that NGS is not reimbursed for squamous cell carcinoma [SCC] patients in France), two (4.0\%) with large-cell neuroendocrine carcinoma, one $(2.0 \%)$ with large-cell carcinoma, one $(2.0 \%)$ with sarcomatoid carcinoma, one $(2.0 \%)$ with undifferentiated carcinoma, four $(8.0 \%)$ only had liquid biopsy, four (8.0\%) had uninterpretable NGS due to lack of DNA amplification, and finally, adequate tumor material was exhausted for five (10.0\%) patients. Comparison of the clinical and pathological features of included patients and patients with no available NGS, is presented in Supplementary Table 1. There were no significantly different characteristics between patients with or without NGS according to age, gender, smoking, performance status. However, SCC histology and nivolumab monotherapy were more frequent and the number of lines more important in the non NGS group, reflecting the specific immunotherapy registrations and indications in the SCC sub-type. Table 2 reports the baseline characteristics of patients in the TP53mutated and TP53-wild-type groups. Overall, 57 (79.2\%) patients were younger than 70 years of age at $\mathrm{ICI}$ initiation, and median age at $\mathrm{ICI}$ initiation was 61 (range: 3383) years; 52 (72.2\%) patients were male, and 53 (73.6\%) were current smokers or recent quitters (<10 years). There were 53 (73.6\%) patients with adenocarcinoma and 19 (26.4\%) with other histological subtypes, 11 (15.3\%) of which were SCC, three $(4.2 \%)$ sarcomatoid carcinoma, one $(1.4 \%)$ with large-cell neuroendocrine carcinoma features, one (1.4\%) with large-cell carcinoma, and three (4.2\%) with very undifferentiated carcinomas not otherwise specified (NOS). NGS was performed in these patients because they were light or never-smokers, suggesting the possibility of potentially targetable addictive oncogenic alterations. On ICI initiation, 67 (93.1\%) patients were metastatic; five $(6.9 \%)$ presented with Stage IIIA, four of whom were refused surgery and radiotherapy due to unresectable tumors or associated 
comorbidities, and one suffered early localized relapse following platinum-based chemotherapy and thoracic irradiation. ICI was administered to $20(27.8 \%)$ in first line and to $52(72.2 \%)$ in second line or after. Most patients $(n=59,81.9 \%)$ received nivolumab alone. There were $12(16.7 \%)$ participating in clinical trials assessing ICI in combination with another $\mathrm{ICI}(\mathrm{n}=8)$ or with platinum-based chemotherapy $(n=4)$ in a first-line setting. On ICI initiation, 39 (54.2\%) patients had a performance status (PS) of 1 or less. A total of 25 (34.8\%) patients harbored KRAS mutations, two (2.8\%) harbored EGFR activating mutations, but none had ALK or ROS1 rearrangement. There were 41 (56.9\%) harboring TP53 mutations and 31 (43.1\%) were TP53 wild-type. Of the 65 (90.3\%) patients with available tumor PD-L1 immunohistochemical data with E1L3N monoclonal antibody, 36 (55.4\%) expressed PD-L1 $\geq 50 \%, 20$ (30.8\%) from 1 to $49 \%$, and nine (13.8\%) produced negative results.

Overall, the median follow-up was 15.2 months (95\% Cl 10.3-17.4 months). Median OS was 15.4 months (95\% Cl 7.8 months to not reached [NR]), and median PFS was 3.7 months $(95 \% \mathrm{Cl} 1.8$ to 4.8 months). Of the 41 patients with TP53 mutation, we retrieved 37 distinct mutations. Missense and nonsense mutations were found in 30 (73.2\%) and seven (17.1\%) patients, respectively. Three mutations (7.3\%) were not found in the IARC database. As reported in Figure 1, most of the mutations affected exons 5, 6, 7, and 8. In total, $25(61.0 \%)$ of the alterations were transversions ( $\square$ C , $\mathrm{A} \square \mathrm{T}, \mathrm{G} \square \mathrm{C}$ or $\mathrm{G} \square \mathrm{T}$ ) and 14 (34.1\%) were G-to-T transversions. Of the missense mutations, $27(90.0 \%)$ disabled the TP53 gene and three (10.0\%) caused partial functional impairment of the TP53 protein. Six (14.6\%) mutations were located in hotspot regions of the TP53 gene, in the core DNA-binding domain (codons 157, 158, 248, and 273). In the overall population, 25 (34.8\%) patients harbored KRAS 
mutations and $11(15.3 \%)$ both KRAS and TP53 mutations. Four (5.6\%) patients harbored STK11 mutations, two (2.8\%) of whom also harbored TP53 mutations.

Of note, as previously reported [20], TP53 mutations were significantly associated with smoking (chi2 test, $\mathrm{p}=0.009$ ). We also found a significant correlation between the occurrence of TP53 and PD-L1 tumor expression (chi2 test, $\mathrm{p}=0.002$ ) (Table 2). In the TP53-mutated group, 16 deaths were observed out of 41 patients (39.0\%) versus 20 out of 31 patients (64.5\%) in the TP53-wild-type group. In the TP53mutated group, $26(63.4 \%)$ patients had progressed or were dead at data cutoff versus 25 (80.6\%) patients in the TP53-wild-type group. Median OS in the TP53mutated group was 18.1 months $(95 \% \mathrm{Cl} 6.6$ months to NR) versus 8.1 months (95\% $\mathrm{Cl} 2.2$ to 14.5 months) in the TP53-wild-type group (HR: $0.48 ; 95 \% \mathrm{Cl} 0.25-0.95$; $\mathrm{p}=0.04$ ) (Fig. 2A). Median PFS was also significantly longer in the TP53-mutated group compared to the TP53-wild-type group (4.5 months, 95\% Cl 2.8 to 18.1 months versus 1.4 months, $95 \% \mathrm{Cl}: 1.1$ to 3.5 months; HR: 0.53 ; $95 \% \mathrm{Cl} 0.30-0.95$; $\mathrm{p}=0.03]$ ) (Fig. 2B). ORR was significantly higher in patients with TP53 mutations compared to TP53-wild-type patients (51.2\% versus $20.7 \%$, respectively; $p=0.013$ ), as was DCR (68.3\% versus $41.4 \%$, respectively; $p=0.03)$. We did not find any statistically significant interaction between TP53 status and PD-L1 expression either for PFS or OS, possibly because of a lack of power (data not shown).

As described in the materials and methods section, based on their p-value in univariate analysis, variables analyzed in the PFS multivariate model were age, smoking status, PS, histological subtype, TP53 mutational status and PD-L1 expression level, while variables analyzed in the OS multivariate model were gender, age, smoking status, PS and TP53 mutational status. In multivariate analysis, performed in 65 patients with complete PD-L1 staining data, TP53 mutations were 
associated with a non-significant increase of PFS in patients receiving $\mathrm{ICl}$, with a $29 \%$ decrease risk of progression or death (HR: [0.35-1.41], $p=0.32$ ). Accordingly, TP53 mutations significantly correlated with longer OS in these patients, with a $65 \%$ decrease of death risk (HR: 0.35 [0.16-0.77], $p=0.009$ ), suggesting that patients with TP53 mutations derive a larger benefit from ICI, possibly due to TP53's role in genomic stability control (Table 2S). Multivariate analyses performed in the whole population including the seven patients without available PD-L1 data, showed the very same prognostic value of TP53 mutations (data not shown).

\section{Discussion}

In this study with mostly "real-life" patients, TP53 gene mutations in aNSCLC patients treated with $\mathrm{ICl}$ were found to correlate with better OS, PFS, and ORR, compared with TP53-wild-type patients, with the OS effect still present when adjusting for other important prognosis factors.

These results are striking since TP53 mutations have repeatedly been associated with worse survival and resistance to classical chemotherapy in lung and breast cancers, especially when TP53 mutations lead to a change in conformation of the central domain of mutant p53, which is the essential component in this interaction with $\mathrm{p} 73$, or when they associate with arginine codon 72 polymorphism, which also drives the interaction with $p 73[21,22]$. In our population of 72 patients treated with $\mathrm{ICl}$, median OS and PFS were 15.4 and 3.7 months, respectively, consistent with prior studies assessing ICI in aNSCLC patients in first or later lines [1-3]. Median OS in the TP53-mutated group and TP53-wild-type group were 18.1 and 8.1 months, respectively (HR: $0.48 ; p=0.04$ ). These findings support the hypothesis that TP53 mutations are associated with favorable outcomes under ICI treatment. 
Our study therefore independently confirms the data recently published of the CA209-227 trial on the predictive value of TMB for PFS in patients receiving PD-1 and CTLA-4 blockers $[15,23]$. In this analysis of individual genes' contribution to predicting response or resistance to combination immunotherapy, some gene mutations such as STK11 or PTEN were confirmed to be exclusively associated with resistance. Conversely, only TP53 mutations are enriched in responders and associated with increased mutation burden in patients treated by combination immunotherapy, along with the Cancer Genome Atlas, publicly-available NSCLC data.

To the best of our knowledge, our study is the first to demonstrate the association of TP53 mutational status assessed by NGS not only with response or PFS but also with OS, in an ICl therapy context. In the Dong et al. study involving 30 NSCLC patients treated with pembrolizumab, PFS was the only endpoint found to be significantly lengthened in TP53-mutated patients as compared to TP53-wild-type patients $(p=0.042)$ [11]. Recent studies have suggested that PFS and ORR are not appropriate surrogates for $\mathrm{OS}$ for $\mathrm{ICl}$ treatment owing to the incidence of pseudoprogression with delayed clinical benefit and the uncertainty that surrounds RECIST or immune RECIST criteria use to evaluate tumor response in such ICItreated patients. Actually a recent study has suggested that only 6-month PFS could be a surrogate for OS [24]. Therefore, OS remains the most reliable and meaningful measure of clinical benefit under ICI $[25,26]$.

Consistent with how the TP53 mutational landscape in lung cancer is described in the literature, $56.9 \%$ of the patients in our cohort harbored TP53 mutations, $73.2 \%$ of which were missense mutations [16]. As previously reported, $34.1 \%$ of reported mutations in our cohort were G-to-T transversions, considered a tobacco exposure 
signature in lung cancer, and resulting from DNA adduct formation from carcinogens in tobacco smoke, prominently polycyclic aromatic hydrocarbons and nicotinederived nitrosamine ketone [27-29]. Interestingly, most of the recorded TP53 mutations resulted in disabled TP53 genes (65.9\%), a molecular event that causes a wide array of downstream cellular consequences. First, inactivating TP53 mutations hamper TP53 canonical functions of tumor suppressor by impeding its transcriptional activity involved in promoting cell cycle arrest, damaged DNA repair, cellular senescence, and apoptosis [13]. As such, loss-of-function TP53 mutations ultimately lead to a marked enhancement of tumor genomic instability [30], thereby spurring tumor immunogenicity by generating tumor neo-antigens or resulting in mutations in dominant oncogenes, such as KRAS [31]. That gain in tumor immunogenicity fueled by the loss of TP53 may also cause increased recruitment of cytotoxic T lymphocytes into the tumor stroma, consequently potentiating the efficacy of ICI [32]. Additionally, it has been proven that destabilizing TP53 mutations could lead to altered unfolded TP53 proteins, which may also independently constitute tumor-specific antigens enhancing $\mathrm{T}$ cell reactivity, when involving major histocompatibility (MHC) Class I molecules [33].

Conversely, wild-type TP53 is thought to also be involved in PD-L1 expression regulation. As shown by Cha et al. in 323 surgically-resected lung adenocarcinoma cases, TP53 mutated status, as assessed in this study by positive immunochemistry staining with anti-TP53 antibody, which is only partly correlated TP53 mutations, was actually associated with higher PD-L1 expression in tumor cells [14]. However, evaluating TP53 mutational status with immunohistochemical assay appears questionable, since mechanisms other than mutations could lead to intracellular accumulation of TP53 protein, which also depends on the type of TP53 mutation [34]. 
It has been also demonstrated by Cortez et al., in vitro and in a syngeneic mouse model presenting with lung adenocarcinoma harboring R172H TP53 mutation, that TP53 regulates PD-L1 expression by modulating the transcription of a specific microRNA, the miR-34, which directly binds with and inhibits the PD-L1 gene [35]. Therefore, one could speculate that TP53 loss leads to PD-L1 expression derepression in tumor cells, likely optimizing the efficacy of anti-PD1 and anti-PD-L1 inhibitors. However, PD-L1 did not correlate with survival, while multivariate analysis showed TP53 mutations were independently associated with better OS, suggesting that expression of PD-L1 did not represent a confounding factor in our series. In recent years, wild-type TP53 has also been hailed as a guardian of immune integrity. One of TP53's most essential roles has been shown to be obviating autoimmunity, notably by modulating the induction of $\mathrm{T}$ regulatory cells through TP53- mediated Foxp3 transcription [36,37]. Thus, TP53 loss may also reduce tumor immunotolerance and foster induction of immune cytotoxic effectors in inhibiting $\mathrm{T}$ cell polarization towards $\mathrm{T}$ regulatory cell phenotype.

Our study encountered several limitations: first, its retrospective nature, with the lack of blinded independent assessment of objective response, although ORR was a secondary endpoint. Second, the limited size of our single-center series could have resulted in bias and lack of statistical power. Notably, keeping in mind that targeted somatic NGS is only routinely performed in our center for lung non-squamous carcinoma, an essential bias consists in the fact that $73.6 \%$ of patients in our cohort presented with adenocarcinoma. However, it has been demonstrated that the type of hotspot mutations of TP53 gene were similar between lung adenocarcinoma and squamous lung cancer, especially in current or former smokers, although the incidence of these mutations was notably lower, for some authors, in 
adenocarcinoma than in squamous cancer subtype ( $46 \%$ versus $81 \%$, respectively) [27]. Additionally, our study was not specifically designed to demonstrate any predictive value of TP53 mutations, giving the lack of a control group of patients not treated by immunotherapy.

Finally, the significant association between TP53 mutations and response or survival under ICI may be merely mediated through $\mathrm{TMB}$, which has been found to positively correlate with favorable outcomes under ICI $[8,9,23]$. In our study, we did not quantify tumor mutation load using an appropriate assay, either WES or the surrogate commercially available Foundation One ${ }^{\mathrm{TM}}$ assay, which is not routinely available in Europe taking into account for its high non-reimbursed cost. Moreover, the aforementioned biological effects of a disabled TP53 gene, including PD-L1 expression de-repression, decreased induction of T-reg lymphocytes or the autoantigenicity of a mutated p53 protein, should not be overlooked for the benefit of genomic instability spurred by a mutated TP53 gene. Thus, we believe that TP53 mutational status could indirectly provide a measure of genetic instability in a quicker, easier, and cheaper way than wide somatic NGS, and should be prospectively tested to check if it could then routinely help clinicians in treatment decision-making.

In conclusion, TP53 mutations are associated with better OS, under ICI treatment in aNSCLC patients compared to patients harboring TP53-wild-type tumors. A putative predictive value of TP53 mutational status should be further assessed in a validation cohort or prospective randomized clinical trial with a control arm devoid of immunotherapy. Moving forward, future studies should attempt to validate a predictive signature of response to $\mathrm{ICl}$, integrating altogether PD-L1 expression and TP53 mutational status as positive factors and STK11, EGFR or PTEN mutations as negative factors. 


\section{References}

[1] J. Brahmer, K.L. Reckamp, P. Baas, L. Crinò, W.E.E. Eberhardt, E. Poddubskaya, et al., Nivolumab versus docetaxel in advanced squamous-cell non-small-cell lung cancer, N. Engl. J. Med. (2015); 373: 123-35.

[2] H. Borghaei, L. Paz-Ares, L. Horn, D.R. Spigel, M. Steins, N.E. Ready, et al., Nivolumab versus docetaxel in advanced nonsquamous non-small-cell lung cancer, N. Engl. J. Med. (2015); 373: 1627-39.

[3] M. Reck, D. Rodríguez-Abreu, A.G. Robinson, R. Hui, T. Csőszi, A. Fülöp, et al., Pembrolizumab versus chemotherapy for PD-L1-positive non-small-cell lung cancer, N. Engl. J. Med. (2016); 375: 1823-33.

[4] D.T. Le, J.N. Uram, H. Wang, B.R. Bartlett, H. Kemberling, A.D. Eyring, et al., PD1 blockade in tumors with mismatch-repair deficiency, N. Engl. J. Med. (2015); 372: 2509-20.

[5] D.T. Le, J.N. Durham, K.N. Smith, H. Wang, B.R. Bartlett, L.K. Aulakh, et al., Mismatch repair deficiency predicts response of solid tumors to PD-1 blockade, Science. (2017); 357: 409-13.

[6] E.B. Garon, N.A. Rizvi, R. Hui, N. Leighl, A.S. Balmanoukian, J.P. Eder, et al., Pembrolizumab for the treatment of non-small-cell lung cancer, N. Engl. J. Med. (2015) 372: 2018-28.

[7] S. Champiat, L. Dercle, S. Ammari, C. Massard, A. Hollebecque, S. Postel- Vinay, et al., Hyperprogressive disease is a new pattern of progression in cancer patients treated by anti-PD-1/PD-L1, Clin. Cancer Res. (2017); 23:1920-28.

[8] N.A. Rizvi, M.D. Hellmann, A. Snyder, P. Kvistborg, V. Makarov, J.J. Havel, et al., Mutational landscape determines sensitivity to PD-1 blockade in non-small cell lung cancer, Science. (2015); 348: 124-28. 
[9] H. Rizvi, F. Sanchez-Vega, K. La, W. Chatila, P. Jonsson, D. Halpenny, et al., Molecular determinants of response to anti-programmed cell death (PD)-1 and antiprogrammed death-ligand (PD-L)-ligand 1 blockade in patients with nonsmall- cell lung cancer profiled with targeted next-generation sequencing, J. Clin. Oncol. (2018); 36: 633-41.

[10] F. Skoulidis, L.A. Byers, L. Diao, V.A. Papadimitrakopoulou, P. Tong, J. Izzo, et al., Co-occurring genomic alterations define major subsets of KRAS-mutant lung adenocarcinoma with distinct biology, immune profiles, and therapeutic vulnerabilities, Cancer Discov. (2015); 5: 860-77.

[11] Z.-Y. Dong, W.-Z. Zhong, X.-C. Zhang, J. Su, Z. Xie, S.-Y. Liu, et al., Potential predictive value of TP53 and KRAS mutation status for response to PD-1 blockade immunotherapy in lung adenocarcinoma, Clin. Cancer Res. ( 2017); 23 :3012-24

[12] D.R. Spigel, A. Betzig Schrock, D. Fabrizio, Total mutation burden (TMB) in lung cancer (LC) and relationship with response to PD-1/PD-L1 targeted therapies, J Clin Oncol. (2016); 34: 9017-17.

[13] E.R. Kastenhuber, S.W. Lowe, Putting p53 in Context, Cell. (2017); 170: 106278.

[14] Y.J. Cha, H.R. Kim, C.Y. Lee, B.C. Cho, H.S. Shim, Clinicopathological and prognostic significance of programmed cell death ligand-1 expression in lung adenocarcinoma and its relationship with p53 status, Lung Cancer (2016); 97: 73-80. [15] M.D. Hellmann, T. Nathanson, H. Rizvi, B.C. Creelan, F. Sanchez-Vega, A. Ahuja, et al., Genomic features of response to combination immunotherapy in patients with advanced non-small-cell lung cancer, Cancer Cell. (2018); 33: 853-61 
[16] M. Olivier, M. Hollstein, P. Hainaut, TP53 mutations in human cancers: origins, consequences, and clinical use, Cold Spring Harb. Perspect. Biol. (2010); 2: a001008. doi: 10.1101/cshperspect.a001008.

[17] G. Zalcman, E. Bergot, P. Hainaut, Breast-cancer stromal cells with TP53 mutations., N. Engl. J. Med. 10 (2008) 1635-6; author reply 1636.

[18] J. Pluvy, S. Brosseau, C. Naltet, M.-A. Opsomer, A. Cazes, C. Danel, et al., Lazarus syndrome in nonsmall cell lung cancer patients with poor performance status and major leukocytosis following nivolumab treatment, Eur. Respir. J. 50 (2017); 50: pii: 1700310. doi: 10.1183/13993003.00310-2017

[19] J. Adam, N. Le Stang, I. Rouquette, A. Cazes, C. Badoual, H. Pinot-Roussel, et al., Multicenter French harmonization study for PD-L1 IHC testing in non-small cell lung cancer, Ann. Oncol. (2018); 2: 953-58.

[20] A.R. Halvorsen, L. Silwal-Pandit, L.A. Meza-Zepeda, D. Vodak, P. Vu, C. Sagerup, et al., TP53 mutation spectrum in smokers and never smoking lung cancer patients, Front. Genet. 7 (2016); 85: doi: 10.3389/fgene.2016.00085.

[21] R.R. Wallace-Brodeur, S.W. Lowe, Clinical implications of p53 mutations, Cell. Mol. Life Sci. (1999); 55: 64-75

[22] D. Bergamaschi, M. Gasco, L. Hiller, A. Sullivan, N. Syed, G. Trigiante, et al., p53 polymorphism influences response in cancer chemotherapy via modulation of p73-dependent apoptosis, Cancer Cell. 3 (2003) 387-402.

[23] M.D. Hellmann, T.-E. Ciuleanu, A. Pluzanski, J.S. Lee, G.A. Otterson, C. Audigier-Valette, et al., Nivolumab plus ipilimumab in lung cancer with a high tumor mutational burden, N. Engl. J. Med. (2018); 378:2093-2104

[24] G. Ritchie, H. Gasper, J. Man, S. Lord, I. Marschner, M. Friedlander, et al., Defining the most appropriate primary end point in phase 2 trials of 
immunecheckpoint inhibitors for advanced solid cancers: a systematic review and meta-analysis, JAMA Oncol. (2018) ;4: 522-28.

[25] H.L. Kaufman, L.H. Schwartz, W.N. William, M. Sznol, M. del Aguila, C. Whittington, Evaluation of clinical endpoints as surrogates for overall survival in patients treated with immunotherapies, J Cancer Res Clin Oncol. (2018); 144:22452261

[26] S.L. Mushti, F. Mulkey, R. Sridhara, Evaluation of overall response rate and progression-free survival as potential surrogate endpoints for overall survival in immunotherapy trials, Clin. Cancer Res. (2018); 24: 2268-75.

[27] D.L. Gibbons, L.A. Byers, J.M. Kurie, Smoking, p53 mutation, and lung cancer, Mol. Cancer Res. (2014); 12: 3-13.

[28] L. Ding, G. Getz, D.A. Wheeler, E.R. Mardis, M.D. McLellan, K. Cibulskis, et al., Somatic mutations affect key pathways in lung adenocarcinoma, Nature. (2008); 455: 1069-75.

[29] S.S. Hecht, Tobacco smoke carcinogens and lung cancer, J. Natl. Cancer Inst. (1999); 91: 1194-10.

[30] G. Ciriello, M.L. Miller, B.A. Aksoy, Y. Senbabaoglu, N. Schultz, C. Sander, Emerging landscape of oncogenic signatures across human cancers, Nat. Genet. (2013); 45:1127-33.

[31] N. McGranahan, C. Swanton, Clonal heterogeneity and tumor evolution: past, present, and the future, Cell. (2017);168: 613-28.

[32] T.N. Schumacher, R.D. Schreiber, Neoantigens in cancer immunotherapy, Science. (2015); 348: 69-74.

[33] K. Shamalov, S.N. Levy, M. Horovitz-Fried, C.J. Cohen, The mutational status of p53 can influence its recognition by human T-cells, Oncoimmunology. (2017); 6 
e1285990.

[34] C. Fouquet, M. Antoine, P. Tisserand, R. Favis, M. Wislez, F. Commo, et al., Rapid and sensitive p53 alteration analysis in biopsies from lung cancer patients using a functional assay and a universal oligonucleotide array: a prospective study, Clin. Cancer Res. (2004);10: 3479-89.

[35] M.A. Cortez, C. Ivan, D. Valdecanas, X. Wang, H.J. Peltier, Y. Ye, et al., PDL1 regulation by p53 via miR-34, J. Natl. Cancer Inst. (2016); 108 doi:10.1093/jnci/djv303

[36] D.-J. Jung, D.-H. Jin, S.-W. Hong, J.-E. Kim, J.-S. Shin, D. Kim, et al., Foxp3 expression in p53-dependent DNA damage responses, J. Biol. Chem. (2010); 285: 7995-8002.

[37] H. Kawashima, H. Takatori, K. Suzuki, A. Iwata, M. Yokota, A. Suto, et al., Tumor suppressor p53 inhibits systemic autoimmune diseases by inducing regulatory T cells, J. Immunol. (2013); 191: 3614-3623. 


\section{Figure Captions}

Figure 1. TP53 and KRAS genotype analysis and co-mutations. (A) TP53 point mutations and locations in dataset. (B) Type of TP53 mutations and exon distribution. (C) TP53 mutation effect on protein structure and transcriptional activity. (D) KRAS point mutations in dataset. (E) Distribution of TP53, KRAS, STK11, and EGFR cooccurring mutations, as depicted in a proportional Venn diagram.

NA: non appropriate; SH3-like: src homology-3-like domain; NES: nuclear export signal.

Figure 2. Kaplan-Meier plots showing (A) overall survival and (B) progression-free survival of patients with and without TP53 mutations from ICI initiation.

NR: Not Reached. 
A.

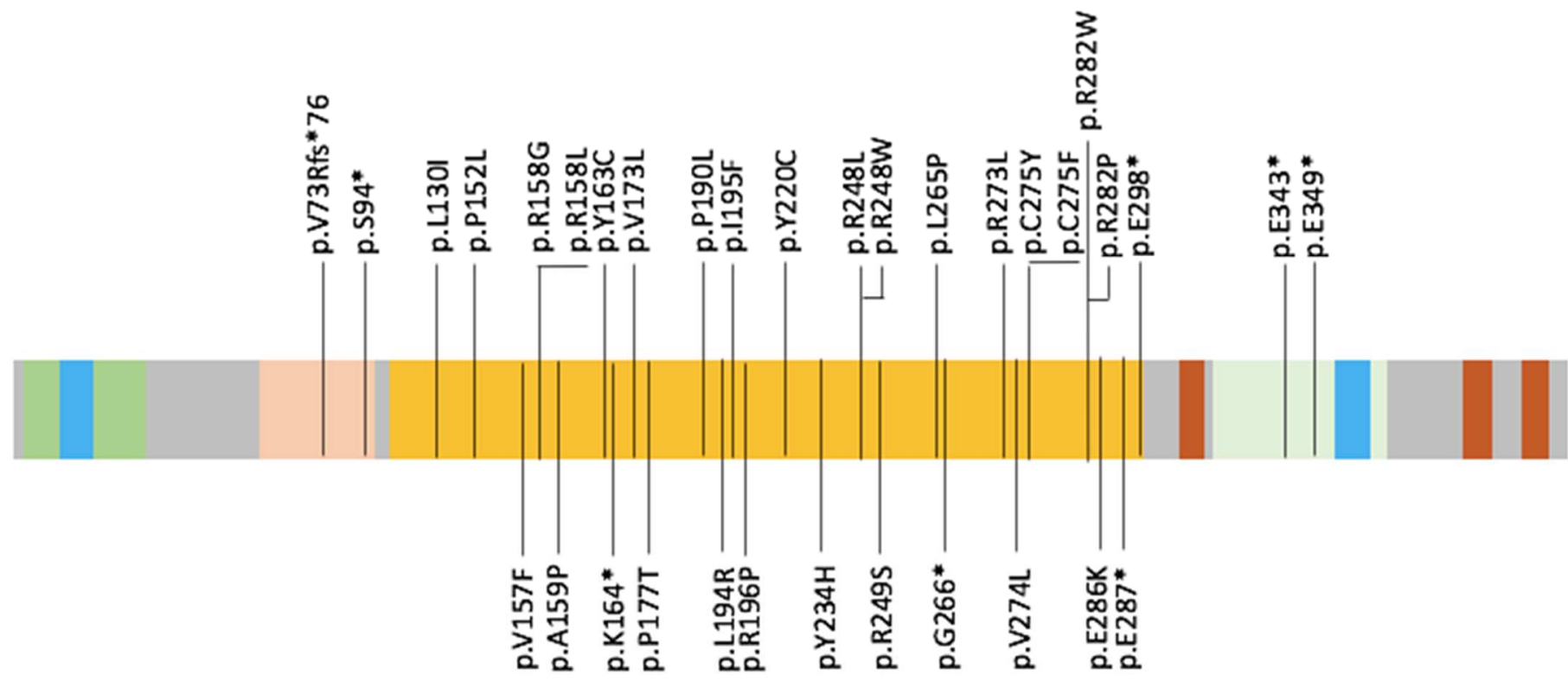

Transactivation

Nuclear Export Signal

Proline-rich
Sequence-specific DNA binding

Nuclear Localization Signal

Oligomerization 
B.

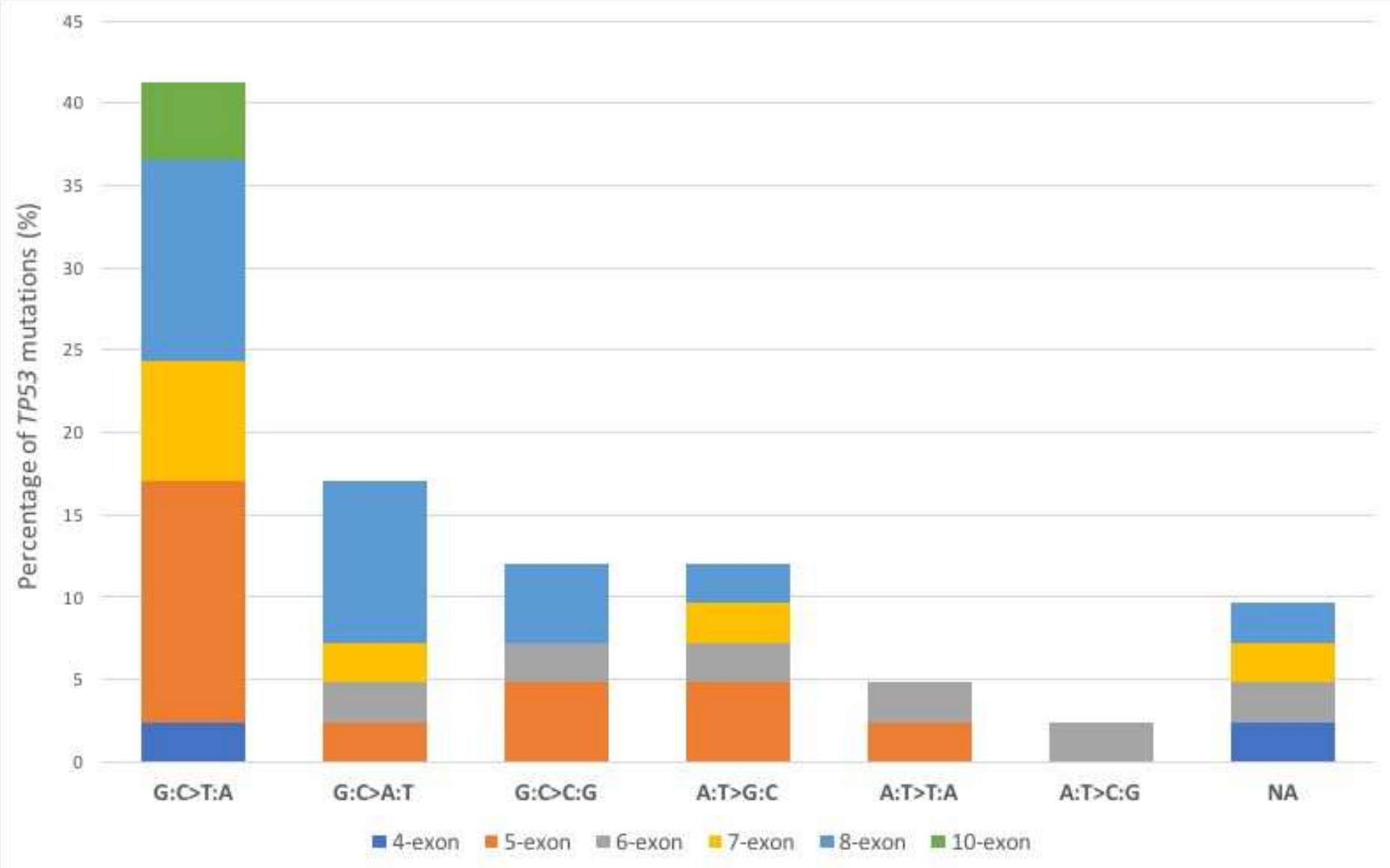

C.

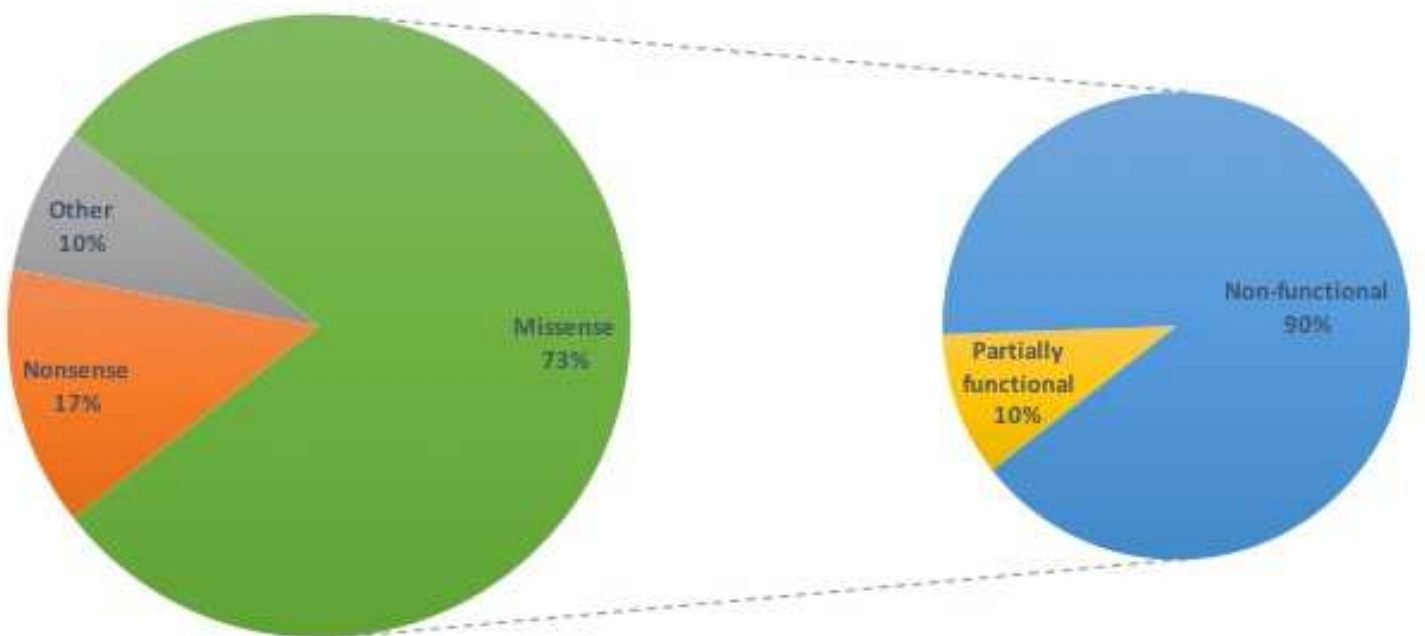


D.

E.

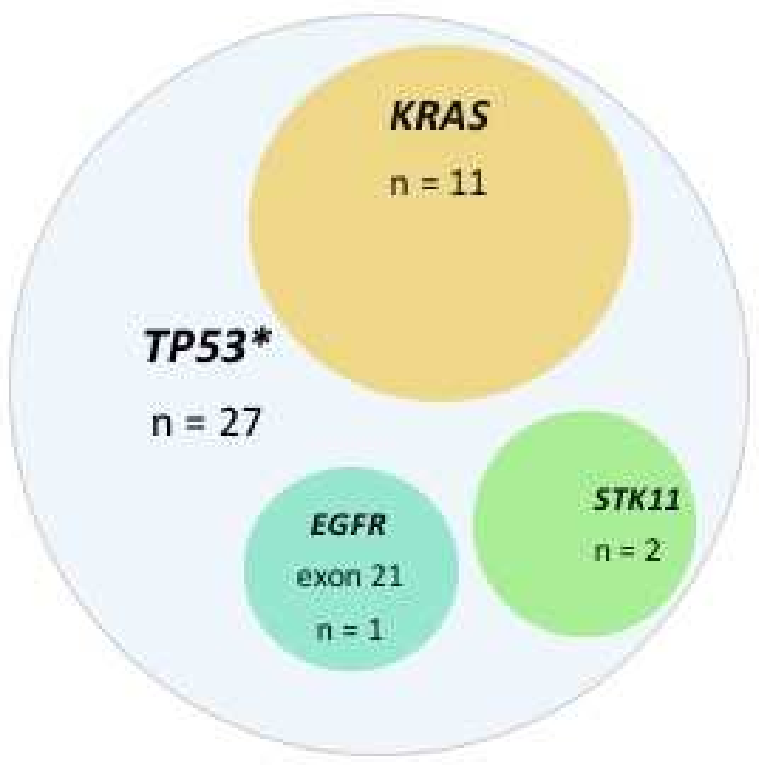

*TP53 $(\mathrm{n}=27)$ represents number of patients with TP53 mutations without KRAS, EGFR or STK11 mutations. 
A.

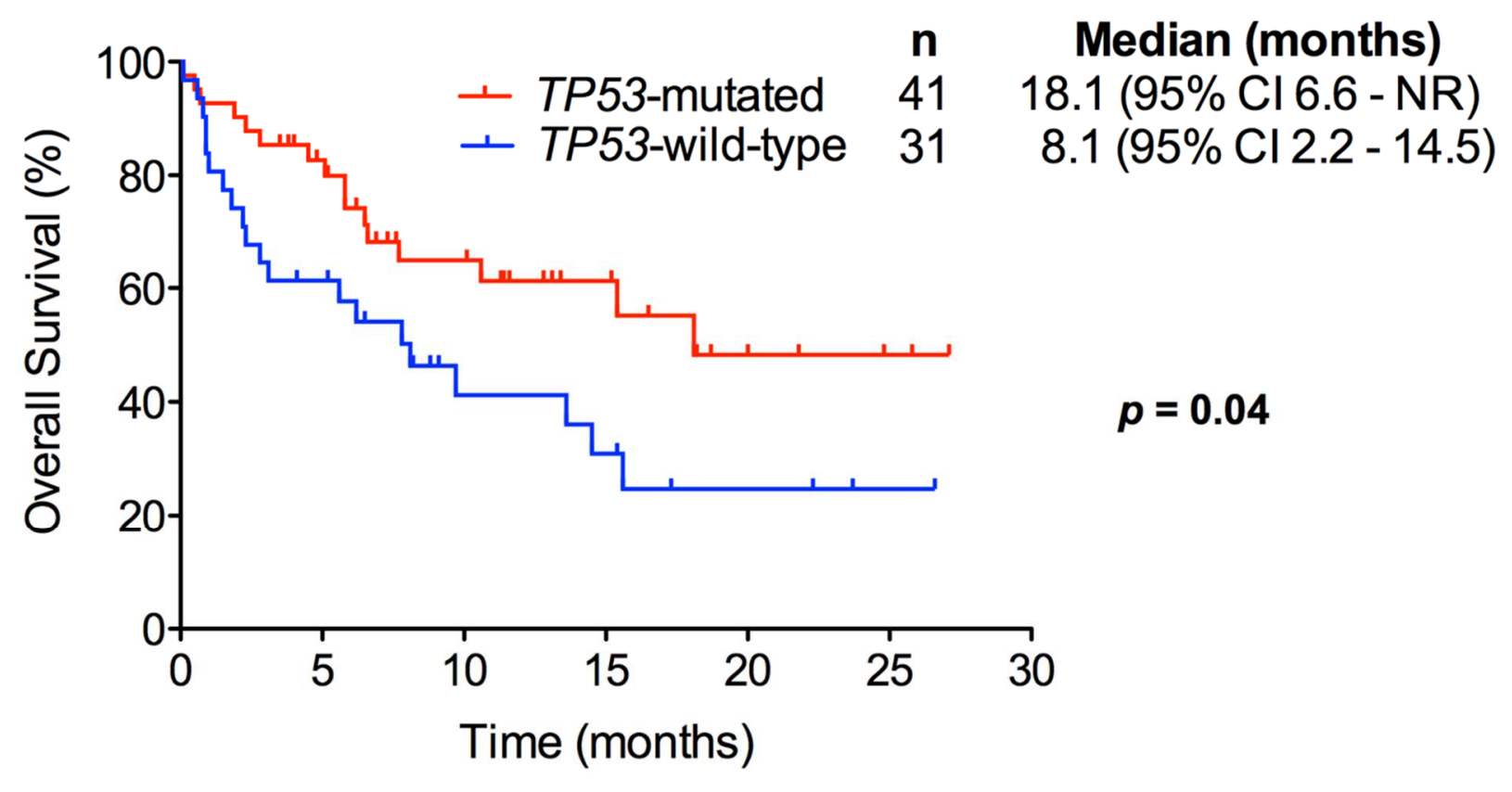

Patients at risk

$\begin{array}{lrrrrrrr}\text { TP53-mutated } & 41 & 31 & 20 & 12 & 5 & 3 & 0 \\ \text { TP53-wild-type } & 31 & 19 & 9 & 7 & 4 & 2 & 0\end{array}$

B.

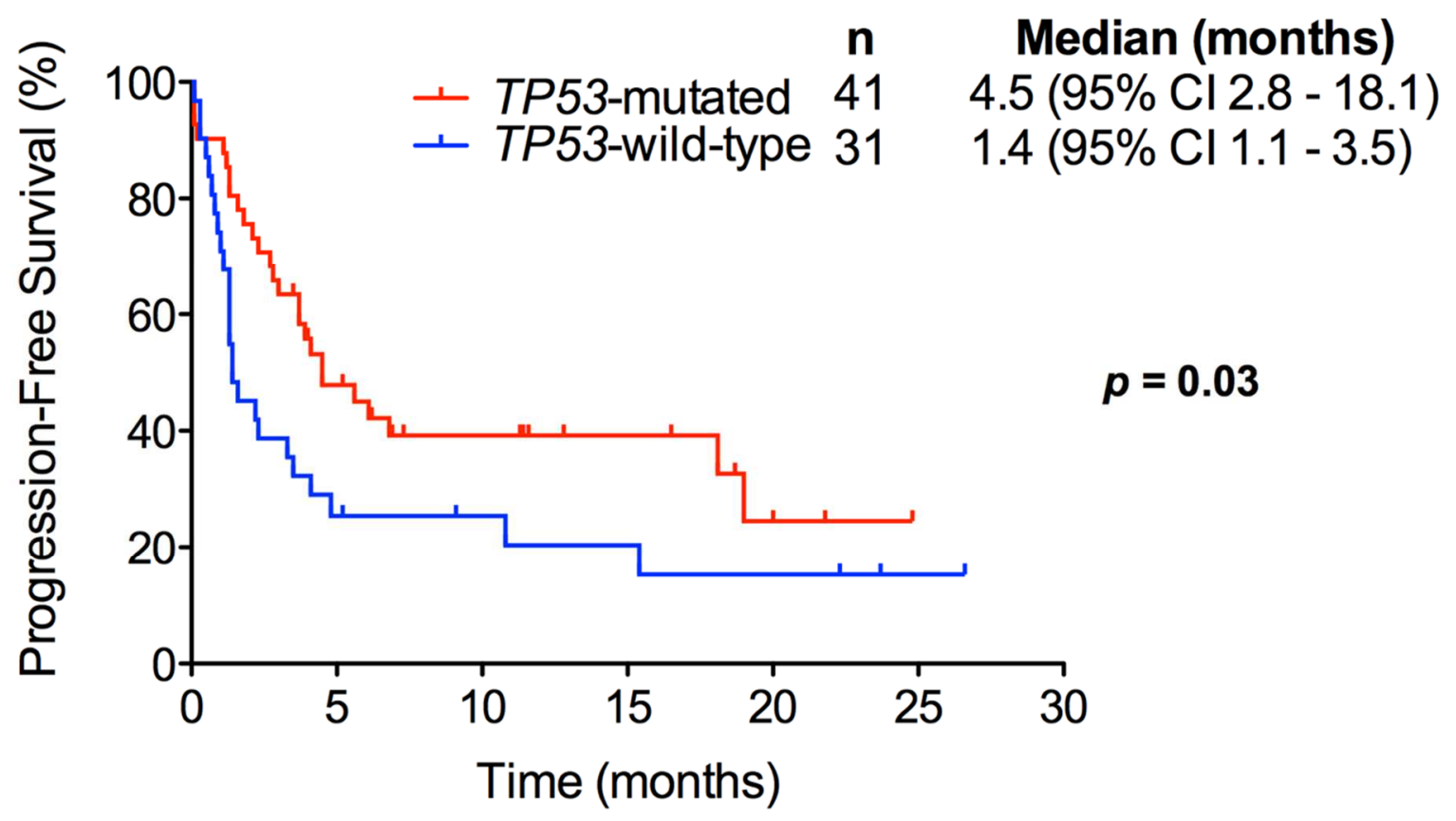

Patients at risk TP53-mutated TP53-wild-type

$\begin{array}{rrrrrrr}41 & 20 & 12 & 8 & 3 & 1 & 0 \\ 31 & 8 & 6 & 5 & 4 & 2 & 0\end{array}$


Table 1. Genes Analyzed Using Next-Generation Sequencing in Patients with Advanced Non-Small-Cell Lung Cancer in routine care

\begin{tabular}{ll}
\hline EGFR (exon 12/18/19/20/21), NM_005228.3 & \\
\hline KRAS (exon 2/3/4), NM_033360.3 & FBXW7 (exon 5/8/9/10/11), NM_012179.3 \\
BRAF (exon 11/15), NM_004333.4 & $\begin{array}{l}\text { ERBB4 (exon 3/4/6/7/8/9/10/12/15/23), } \\
\text { NM_005235.2 }\end{array}$ \\
MAP2K1 (exon 2), NM_002755.3 & KIT (exon 8/9/11/13/14/17/18), NM_000222.2 \\
CTNNB1 (exon 3), NM_001904.3 & MET (exon 2/14/15/16/17/18/19/20, intron13/14), \\
SMAD4 (exon 3/5/6/8/9/10/11/12), & NM_001127500.1 \\
NM_005359.5 & PTEN (exon 1/3/6/7/8), NM_000314.4 \\
NOTCH1 (exon 26/27), NM_017617.3 & NRAS (exon 2/3/4), NM_002524.4 \\
FGFR2 (exon 7/9/12.14), NM_022970.3 & STK11 (exon 1/4/5/6/8), NM_000455.4 \\
HRAS (exon 2/3/4), NM_NM_001130442.2 & DDR2 (exon 5/8/12/13/14/15/17), NM_006182.3 \\
PIK3CA (exon 10/14/21), NM_006218.2 & TP53 (exon 2/4/5/6/7/8/10), NM_000546.5 \\
AKT1 (exon 3), NM_001014431.1 & FGFR3 (exon 7/9/14/16/18), NM_001163213.1 \\
ERBB2 (exon 19/20/21), NM_004448.3 & FGFR1 (exon 4/7), NM_001174067.1 \\
ALK (ex. 22/23/24/25), NM_004304.4 & PDGFRA (exon 12/14/18), NM_006206.4 \\
\hline
\end{tabular}


Table 2. Baseline Characteristics of Patients with Non-Small-Cell Lung Cancer Treated with Immune Checkpoint Inhibitors

\begin{tabular}{|c|c|c|c|c|}
\hline $\begin{array}{l}\text { Variables } \\
\text { Median age*, years (range) }^{*}\end{array}$ & $\begin{array}{c}\text { All } \\
\mathbf{n}=72 \\
61(33-83)\end{array}$ & $\begin{array}{c}\text { TP53 mutated } \\
\mathbf{n}=41 \\
61(33-82)\end{array}$ & $\begin{array}{c}\text { TP53 wild-type } \\
\mathbf{n}=31 \\
63(40-83)\end{array}$ & $p$ value \\
\hline Male gender (\%) & $52(72.2)$ & $29(70.7)$ & $23(74.2)$ & 0.84 \\
\hline $\begin{array}{l}\text { Smoking status }(\%) \\
\text { Current or recent quitters } \\
\text { Former or never smokers }\end{array}$ & $\begin{array}{l}53(73.6) \\
19(26.4)\end{array}$ & $\begin{array}{c}35(85.4) \\
6(14.6)\end{array}$ & $\begin{array}{l}18(58.1) \\
13(41.9)\end{array}$ & 0.009 \\
\hline $\begin{array}{l}\text { TNM stage* }(\%) \\
\text { IIIA } \\
\text { IV }\end{array}$ & $\begin{array}{c}5(6.9) \\
67(93.1)\end{array}$ & $\begin{array}{c}4(9.8) \\
37(90.2)\end{array}$ & $\begin{array}{c}1(3.2) \\
30(96.8)\end{array}$ & 0.38 \\
\hline $\begin{array}{l}\text { Histology (\%) } \\
\text { Adenocarcinoma } \\
\text { Other }\end{array}$ & $\begin{array}{l}53(73.6) \\
19(26.4)\end{array}$ & $\begin{array}{l}29(70.7) \\
12(29.3)\end{array}$ & $\begin{array}{c}24(77.4) \\
7(22.6)\end{array}$ & 0.25 \\
\hline $\begin{array}{l}\text { Performance status }{ }^{\star}(\%) \\
\quad 0-1 \\
\geq 2\end{array}$ & $\begin{array}{l}39(54.2) \\
33(45.8)\end{array}$ & $\begin{array}{l}24(58.5) \\
17(41.5)\end{array}$ & $\begin{array}{l}15(48.4) \\
16(51.6)\end{array}$ & 0.39 \\
\hline $\begin{array}{l}\text { Line number (\%) } \\
\quad 1 \\
\geq 2\end{array}$ & $\begin{array}{l}20(27.8) \\
52(72.2)\end{array}$ & $\begin{array}{l}13(31.7) \\
28(68.3)\end{array}$ & $\begin{array}{c}7(22.6) \\
24(77.4)\end{array}$ & 0.44 \\
\hline $\begin{array}{l}\text { Type of ICI (\%) } \\
\text { Pembrolizumab } \\
\text { Nivolumab } \\
\text { Nivolumab + ipilimumab } \\
\text { Nivolumab + chemotherapy }\end{array}$ & $\begin{array}{c}1(1.4) \\
59(81.9) \\
8(11.1) \\
4(5.6)\end{array}$ & $\begin{aligned} 1 & (2.4) \\
32 & (78.0) \\
4 & (9.8) \\
4 & (9.8)\end{aligned}$ & $\begin{array}{c}0(0.0) \\
27(87.1) \\
4(12.9) \\
0(0.0)\end{array}$ & $0.37^{a}$ \\
\hline
\end{tabular}




\begin{tabular}{|c|c|c|c|c|}
\hline \multicolumn{5}{|l|}{ PD-L1, \% (\%) } \\
\hline $\begin{array}{l}<1 \\
1-49 \\
\geq 50 \\
\text { Unknown }\end{array}$ & $\begin{array}{c}9(12.5) \\
20(27.8) \\
36(50.0) \\
7(9.7)\end{array}$ & $\begin{array}{c}4(9.8) \\
7(17.1) \\
25(61.0) \\
5(12.1)\end{array}$ & $\begin{array}{c}5(16.1) \\
13(41.9) \\
11(35.5) \\
2(6.5)\end{array}$ & $0.02^{b}$ \\
\hline \multicolumn{5}{|c|}{$\begin{array}{l}\text { KRAS gene status, exons } 2 / 3 / 4 \\
(\%)\end{array}$} \\
\hline $\begin{array}{l}\text { Mutated } \\
\text { Wild-type }\end{array}$ & $\begin{array}{l}25(34.8) \\
47(65.2)\end{array}$ & $\begin{array}{l}11(26.8) \\
30(73.2)\end{array}$ & $\begin{array}{l}14(45.2) \\
17(54.9)\end{array}$ & 0.11 \\
\hline
\end{tabular}

*at ICl initial

acomparison of nivolumab alone versus other treatments.

${ }^{b}$ comparison of PD-L1 < 1\%, $1-49 \%$ and $\geq 50 \%$.

$\mathrm{ICI}$, immune checkpoint inhibitor; PD-L1, programmed cell death-ligand 1 expression. 
Table 2SA. Univariate and Multivariate Analysis for Overall Survival in Non-Small-Cell Lung Cancer Patients Treated with Immune Checkpoint Inhibitors

\begin{tabular}{|c|c|c|c|c|}
\hline & \multicolumn{2}{|c|}{ Univariate analysis } & \multicolumn{2}{|c|}{ Multivariate analysis } \\
\hline & $\mathrm{HR}(95 \% \mathrm{Cl})$ & $p$-value & $\mathrm{HR}(95 \% \mathrm{Cl})$ & $p$-value \\
\hline \multicolumn{5}{|l|}{ Gender } \\
\hline Male & 1 [Reference] & 0.40 & \multirow[b]{2}{*}{$0.63(0.27-1.36)$} & \multirow[b]{2}{*}{0.26} \\
\hline Female & $0.72(0.34-1.54)$ & & & \\
\hline \multicolumn{5}{|l|}{ Age, years* } \\
\hline$<70$ & 1 [Reference] & 0.73 & \multirow[b]{2}{*}{$1.43(0.49-3.65)$} & \multirow[b]{2}{*}{0.48} \\
\hline$\geq 70$ & $0.86(0.36-2.08)$ & & & \\
\hline \multicolumn{5}{|l|}{ Smoking status } \\
\hline Former or never smoker & 1 [Reference] & 0.39 & \multirow[b]{2}{*}{$3.2(1.30-8.36)$} & \multirow[b]{2}{*}{0.01} \\
\hline Current or recent quitter & $1.40(0.66-2.98)$ & & & \\
\hline \multicolumn{5}{|l|}{ Performans status $^{*}$} \\
\hline$\geq 2$ & 1 [Reference] & 0.007 & \multirow[b]{2}{*}{$0.34(0.16-0.68)$} & \multirow[b]{2}{*}{0.003} \\
\hline $0-1$ & $0.40(0.20-0.78)$ & & & \\
\hline \multicolumn{5}{|l|}{ Histologic subtype } \\
\hline Non adenocarcinoma & 1 [Reference] & 0.51 & - & \multirow{2}{*}{-} \\
\hline Adenocarcinoma & $0.78(0.38-1.63)$ & & & \\
\hline \multicolumn{5}{|l|}{ Line number } \\
\hline 1 & 1 [Reference] & 0.48 & - & \multirow[t]{2}{*}{-} \\
\hline$\geq 2$ & $1.33(0.61-2.92)$ & & & \\
\hline \multicolumn{5}{|l|}{ TP53 mutation } \\
\hline No & 1 [Reference] & 0.04 & \multirow{3}{*}{$0.35(0.16-0.77)$} & \multirow[b]{2}{*}{0.009} \\
\hline Yes & $0.5(0.26-0.96)$ & & & \\
\hline \multicolumn{4}{|l|}{ PD-L1, \%** } & \\
\hline$\geq 50$ & 1 [Reference] & 0.56 & - & \multirow[t]{2}{*}{-} \\
\hline $1-49$ & $1.22(0.62-2.39)$ & & & \\
\hline
\end{tabular}




\begin{tabular}{lccc}
\hline KRAS mutation & & \\
Yes & 1 [Reference] & 0.86 & - \\
No & $1.06(0.52-2.17)$ & & - \\
\hline
\end{tabular}

*at ICI initiation.

${ }^{* *}$ PD-L1 expression was only available in 65 patients out of $72(90.3 \%)$.

ICl, Immune checkpoint inhibitor; PD-L1, programmed cell death-ligand 1 expression; HR, hazard ratio; $\mathrm{Cl}$, confidence interval. 
Table 2SB. Univariate and Multivariate Analysis for Progression-Free Survival in Non-Small-Cell Lung Cancer Patients Treated with Immune Checkpoint Inhibitors

\begin{tabular}{|c|c|c|c|c|}
\hline & \multicolumn{2}{|c|}{ Univariate analysis } & \multicolumn{2}{|c|}{ Multivariate analysis } \\
\hline & $\mathrm{HR}(95 \% \mathrm{Cl})$ & $p$-value & $\mathrm{HR}(95 \% \mathrm{Cl})$ & $p$-value \\
\hline \multicolumn{5}{|l|}{ Gender } \\
\hline Male & 1 [Reference] & 0.51 & \multirow{2}{*}{\multicolumn{2}{|c|}{-}} \\
\hline Female & $0.80(0.41-1.55)$ & & & \\
\hline \multicolumn{5}{|l|}{ Age, years* } \\
\hline$<70$ & 1 [Reference] & 0.20 & \multirow{2}{*}{\multicolumn{2}{|c|}{$1.39(0.53-2.58)$}} \\
\hline$\geq 70$ & $1.59(0.78-3.23)$ & & & \\
\hline \multicolumn{5}{|l|}{ Smoking status } \\
\hline Former or never smoker & 1 [Reference] & 0.16 & \multirow{2}{*}{\multicolumn{2}{|c|}{$1.17(0.48-2.10)$}} \\
\hline Current or recent quitter & $1.55(0.84-2.88)$ & & & \\
\hline \multicolumn{5}{|l|}{ Performans status $^{*}$} \\
\hline $0-1$ & 1 [Reference] & 0.006 & \multirow{2}{*}{\multicolumn{2}{|c|}{$2.21(1.22-4.03)$}} \\
\hline$\geq 2$ & $2.27(1.26-4.08)$ & & & \\
\hline \multicolumn{5}{|l|}{ Histologic subtype } \\
\hline Adenocarcinoma & 1 [Reference] & 0.18 & \multirow{2}{*}{\multicolumn{2}{|c|}{$1.64(0.82-3.27)$}} \\
\hline Non adenocarcinoma & $1.56(0.81-2.98)$ & & & \\
\hline \multicolumn{5}{|l|}{ Line number } \\
\hline 1 & 1 [Reference] & 0.93 & \multirow{2}{*}{-} & \multirow{2}{*}{-} \\
\hline$\geq 2$ & $1.03(0.53-2)$ & & & \\
\hline \multicolumn{5}{|l|}{ TP53 mutation } \\
\hline No & 1 [Reference] & 0.04 & \multirow{2}{*}{\multicolumn{2}{|c|}{$0.71(0.35-1.41)$}} \\
\hline Yes & $0.55(0.31-0.98)$ & & & \\
\hline \multicolumn{5}{|l|}{ PD-L1, \% } \\
\hline$<50$ & 1 [Reference] & 0.13 & \multirow{2}{*}{\multicolumn{2}{|c|}{$0.69(0.37-1.28)$}} \\
\hline$\geq 50$ & $0.64(0.36-1.14)$ & & & \\
\hline
\end{tabular}




\section{KRAS mutation}

No

1 [Reference] $\quad 0.68$

Yes $0.88(0.48-1.63)$

*at $\mathrm{ICl}$ initiation.

${ }^{* *}$ PD-L1 expression was only available in 65 patients out of $72(90.3 \%)$.

ICI, Immune checkpoint inhibitor; PD-L1, programmed cell death-ligand 1 expression; HR, hazard ratio; $\mathrm{Cl}$, confidence interval. 